\title{
Pituitary tumours in MEN1 syndrome — the new insight into the diagnosis and treatment
}

\author{
Damian Rogoziński ${ }^{1}$, Aleksandra Gilis-Januszewska ${ }^{1,2}$, Anna Skalniak ${ }^{1,2}$, Łukasz Kluczyński ${ }^{1,2}$, \\ Jacek Pantofliński ${ }^{1}$, Alicja Hubalewska-Dydejczyk ${ }^{1,2}$ \\ ${ }^{1}$ Endocrinology Department, University Hospital in Krakow, Krakow, Poland \\ ${ }^{2}$ Chair and Department of Endocrinology, Jagiellonian University Medical College, Krakow, Poland
}

\begin{abstract}
Pituitary tumours are a common pathology affecting $15-20 \%$ of the population. Only about $1 \%$ of adenomas are clinically manifested; among them, about two/thirds are hormonally active, most often secreting prolactin or growth hormone. Pituitary tumours are mainly an isolated pathology, without any genetic background. However, the latest studies pay special attention to the possibility of developing an adenoma as a result of genetic mutation. Among pituitary adenomas, the leading group of genetically determined lesions is related to a mutation in AIP or MEN1, followed by PRKAR1A, GRP101, DICER, and SDHx. The genetic basis of these pituitary tumours is related to positive family history, young age of the patient, aggressive clinical process, and resistance to treatment. Pituitary tumours occur in over $40 \%$ of patients with MEN1 syndrome - often in women, they are more than $1 \mathrm{~cm}$ in diameter, and secrete prolactin. They are usually diagnosed in the fourth decade of life and show a worse response to pharmacotherapy than sporadic ones. Confirmation of the genetic background of the pituitary tumour implies measurable implications; it might help to direct the diagnosis in patients' family members, partially predict the development of the disease, and, above all, extend patients' life expectancy. (Endokrynol Pol 2019; 70 (5): 445-452) Key words: pituitary tumours; genetic; MEN1 syndrome; diagnostic; treatment
\end{abstract}

\section{General characteristics of pituitary tumours}

In the times of common availability of imaging studies of the central nervous system, the number of lesions detected in the sella turcica is increasing; the most commonly described pathologies are pituitary adenomas. Organic changes found in the pituitary gland constitute $10-15 \%$ of all intracranial tumours and are the reason for every fourth neurosurgical intervention in the brain area [1,2]. Pituitary microadenomas are found in imaging and autopsy studies in $14.4 \%$ and $22.5 \%$ of patients, respectively [1], while the incidence increases with age (up to $30 \%$ in the sixth decade of life) [3]. Clinically significant tumours account for 1 in 1000 cases in the general population [4, 5]. Most of them are sporadic, but the range of genetically determined cases is estimated to be from $5 \%$ to as much as $40 \%$ [6]. Mutations more often relate to somatic than gender line cells, with the possibility of mosaicism $[6,7]$. Genetically related pituitary tumours are most often the result of mutations in the AIP, MEN1, CDKN1B, GPR101, PRKAR1A, SDHx, NF1, and DICER genes.

\section{MEN1 syndrome}

The first literature reports about the MEN1 syndrome date back to the 1950s, when Underdahl published a review of cases of multiple parathyroid adenomas in patients with acromegaly [8-10]. Wermer is considered to be the author of the genetic model of inheritance; in 1960 he described a case of familial coexistence of the above polyendocrinopathy, raising the suspicion of autosomal-dominant inheritance with high penetrance [11]. Identification of mutations in the MEN1 gene located on chromosome 11q13 was described in 1997 [12]. At the beginning of the twenty-first century, Thakker published the series of papers in which MEN1 syndrome is characterised as a genetically conditioned occurrence of endocrine tumours (autosomal-dominant inheritance with high penetrance), particularly pituitary, parathyroid, and pancreatic islet cells. In addition, carcinoids, adrenocorticotropic tumours, facial angiofibromas, lipomas, and fibromas may also be present in the syndrome [13, 14] (Fig. 1). 


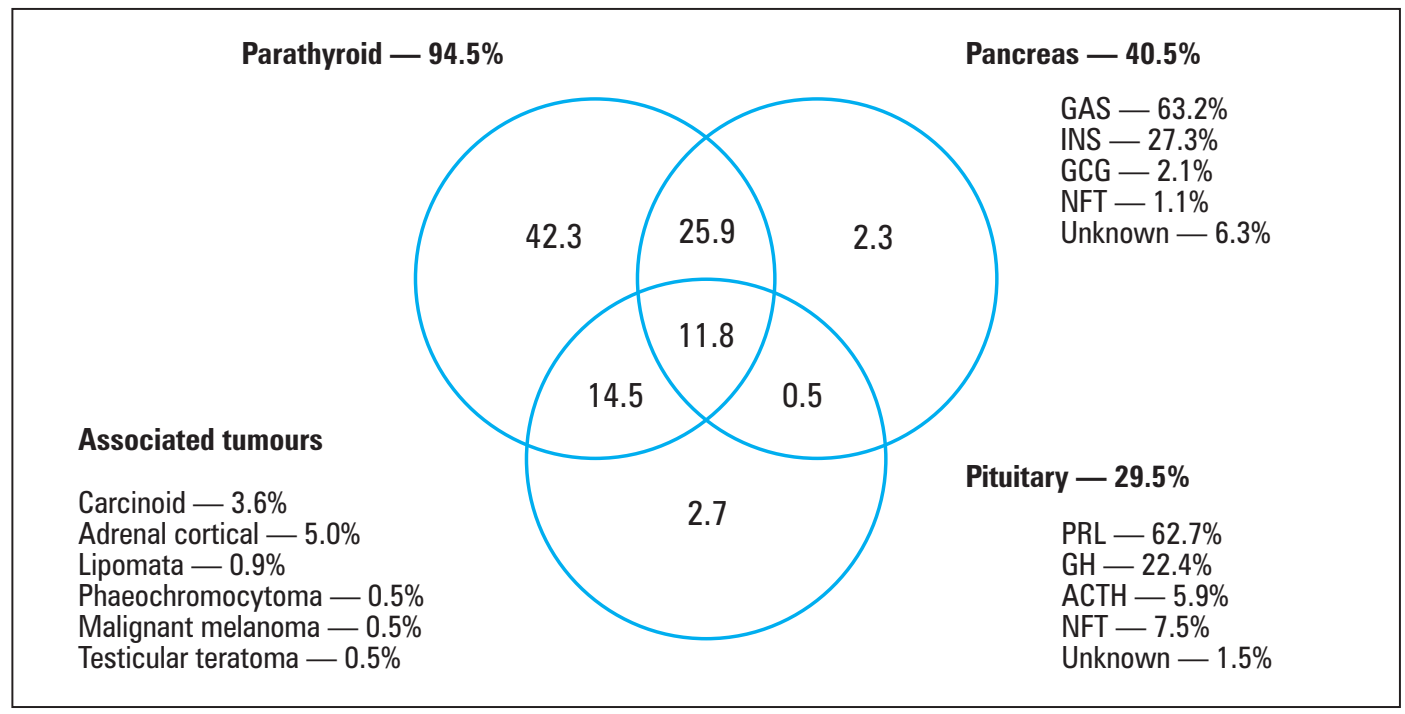

Figure 1. Tumours in MEN1 syndrome in 220 patients. The graph is a schematic presentation of the distribution of 384 tumours found in 220 patients with MEN1 syndrome. The percentages of patients with parathyroid, pituitary, pancreatic, and coexisting tumours are described in the individual fields. For example, $37.7 \%(25.9 \%+11.8 \%)$ of patients had a comorbid pancreatic and parathyroid tumour, while only $2.3 \%$ had an isolated pancreatic tumour. Parathyroid tumours are the most common pathology in MEN1 syndrome (95\%), followed by pancreatic (40.5\%) and pituitary tumours (29.5\%). Others, listed on the left, constitute a small percentage of tumours in MEN1 syndrome. GAS - gastrinoma; INS — insulinoma; GCG - glucagonoma; NFT - non-secretory tumours; PRL — prolactinoma; GH — somatotropinoma; ACTH - adrenocorticotropinoma [14]. Reprinted with the consent of Prof. Thakker and Oxford University Press

\section{Epidemiology}

Based on random post-mortem examinations, the prevalence of MEN1 is estimated to be $0.25 \%$, an average of 1:30,000 people. About $10 \%$ of genetic changes are de novo variants, which are the basis of sporadic disease occurrence; the remaining genetic variants occur in families [13]. MEN1 syndrome occurs in 1-18\% of patients with primary hyperparathyroidism, in 16-38\% of patients with gastrinoma, and in fewer than $3 \%$ of patients with pituitary tumours $[13,15]$. The disease occurs in all age groups; cases of the presentation of the syndrome have been described in patients between five and 81 years of age $[16,17]$. MEN1 is characterised by high penetrance - clinical and biochemical manifestations occur in $80-100 \%$ of patients [18]; whereas, in over $98 \%$ of cases symptoms will occur up to the age of 50 years $[13,16,19]$.

\section{Diagnostics of MEN1 syndrome}

MEN1 syndrome is usually an autosomal-dominant disorder, but it is also possible for it to occur in sporadic cases, i.e. without a positive family history. However, one should remember the limitations resulting from the inability to perform diagnostics in the proband's family (lack of consent for genetic testing, death, late manifestation in the parents [18]), which may result in an unrecognised familial form of the disease. Ultimately, a small number of the cases are the consequences of de novo mutations that will be inherited by the next generation in an autosomal-dominant manner [20]. The fact of inheritance in an autosomal-dominant manner with high penetrance results in a $50 \%$ risk of transferring the genetic variant to the offspring and a $90 \%$ risk of developing the syndrome in people who have inherited the variant. Expert groups have made efforts to establish recommendations systematising current knowledge and the diagnostic and control process [13].

Analysing the unselected population of patients with pituitary tumours, coexistence of primary hyperparathyroidism was found in only $4.8 \%$ of patients. The MEN1 mutation was found in $14.3 \%$ of patients with prolactin tumours. In the majority of patients, the pituitary tumour was diagnosed several years before the diagnosis of hyperparathyroidism. It should be noted that some pituitary tumours were considered sporadic despite the occurrence of other endocrine disorders typical for MEN, so MEN1 syndrome may remain unrecognised in some cases [15].

Diagnosis of the MEN1 syndrome results in significant health effects - for the patients and for their relatives [20-22]. The risk of developing a syndrome in each first-degree relative of a patient with genetically conditioned MEN1 syndrome is 50\% [20]. Thus, it is necessary to conduct a complete diagnostic process, including firstly the confirmation of the mutation and then an active search for typical components of the syn- 
drome [16]. Clinical evaluation with biochemical and radiological tests is performed to detect the tumours.

Diagnosis of MEN1 syndrome is established based on the following criteria:

- clinical evidence, i.e. patients with at least two tumours typical of MEN1 syndrome;

- family premises, i.e. patients with one tumour typical of MEN1 and one first-degree relative with a confirmed MEN1 mutation;

- asymptomatic carriers, i.e. people without clinical and/or biochemical symptoms, in cases with a confirmed MEN1 mutation [14, 16, 20].

\section{Detection of MEN1-related tumours}

Suspicion of MEN1 mutation is associated with the presence of constellations of endocrine disorders. Genetic diagnosis should be carried out in the following cases: (a) in any patient with a positive family history of neuroendocrine tumours of the pancreas, pituitary, or parathyroid gland and with familial occurrence of endocrine system disorders; (b) in patients with Zollinger-Ellison syndrome; (c) in young patients with hormonally active pituitary tumours; (d) in people with multiple pancreatic tumours/neoplasms; (e) in people with hyperparathyroidism and multiple parathyroid gland adenomas /hyperparathyroidism, in particular up to 45 years of age [23]; and (f) in people with a pituitary tumour and hypercalcaemia or other endocrinopathy $[14,24]$.

According to the recommendations of the European Society of Endocrinology published in 2018, genetic tests (searching for pathogenic variants of MEN1 and/or $A I P)$ should be carried out among patients with aggressive pituitary tumours. The test should be determined taking into account the age of the patient at the time of diagnosis and presence of positive family history of pituitary or endocrine system neoplasms. The guidelines indicate the need to look for markers that allow clear differentiation between aggressive and non-aggressive tumours [25]

The identification of a pathogenic variant in the MEN1 gene is tantamount to the need to carry out diagnostics to exclude/confirm the components of the syndrome [16]. The first stage of diagnosis is to select a population of potential carriers of the pathogenic variant of the MEN1 gene (described above) and perform genetic diagnostics. If the presence of the mutant gene is confirmed, genetic counselling should be conducted also among first-degree relatives of the proband (to determine whether the mutation concerns the germline or has appeared de novo in the proband), in addition to the clinical, biochemical, and radiological evaluation of the carrier. The finding of a germinal mutation results in periodic tests of asymptomatic carriers [14].
MEN1 gene testing should include sequence analysis as well as analysis of large deletions within the gene. The deletion analysis is usually performed in the second line if no pathogenic changes are detected in the MEN1 gene sequence in a given patient. The decision to extend the scope of genetic testing should be made on the basis of specific clinical premises. In patients with a negative result of MEN1 mutation screening, other genetic syndromes with hyperparathyroidism should be considered: CDC73 mutations associated with parathyroid gland hyperactivity syndrome (PTH-JT) or calcium receptor (CASR) mutations causing familial hypocalciuric hypercalcaemia (FBHH). Genetic diagnostics for pituitary tumours can be extended to include pathogenic variants in the CDKN1B and AIP genes.

In a symptomatic person (e.g. with hypercalcaemia) with the MEN1 syndrome diagnosed in their family, annual clinical, biochemical, and radiological evaluation should be carried out even if no pathogenic MEN1 variant has been detected in the genetic test. In asymptomatic first-degree relatives of a person with MEN1 syndrome, in which no pathogenic MEN1 variant could be confirmed, a targeted clinical and biochemical evaluation is recommended [14]. This approach is justified in view of a possibly different clinical presentation of MEN1 syndrome even among members of one family [26]. MEN1 syndrome occurs in $90 \%$ of cases on the basis of a pathogenic variant occurring in the family, with a penetrance of up to $100 \%$ [18].

The screening scheme discussed above includes regular monitoring of calcium, parathyroid hormone $(\mathrm{PTH})$, prolactin (PRL), chromogranin $\mathrm{A}(\mathrm{CgA})$, and fasting glucose levels and pituitary gland MRI and $\mathrm{MRI} / \mathrm{CT}$ of the abdominal cavity and chest at a specific frequency (Fig. 2) [14]. The earliest (87\%) and most frequently $(95 \%)$ found abnormality is hypercalcaemia due to primary hyperparathyroidism, which is followed by tumours of the pancreas (41\%) and pituitary gland $(30 \%)[13,14,16]$.

Prospective analyses have shown that biochemical changes might precede the clinical manifestation of the disease by about 10 years [18]. For the early detection of a pituitary tumour in a person with a family history of MEN1 syndrome, measurement of prolactin and IGF- 1 concentration and performing an imaging examination of the sella turcica are recommended. According to the Endocrine Society guidelines published in 2012, diagnostics should be started at the age of five years: hormone measurements should be performed annually, and MRI should be performed every three years [14]. Subsequent studies support this statement [27], but shortening the interval between MRI examinations to two years [28]. In recent years, in light of 


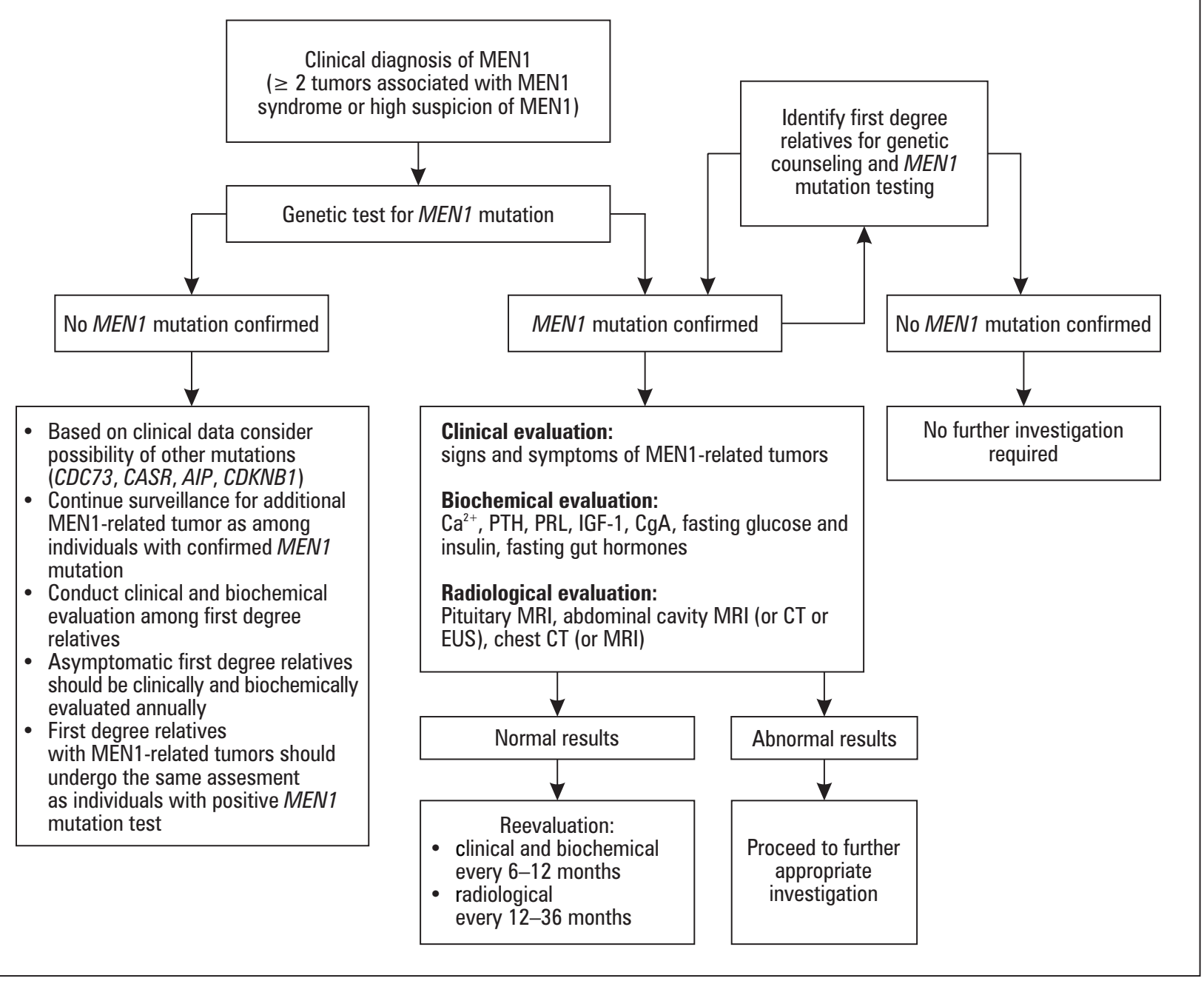

Figure 2. Recommended diagnostic procedures and care for patients with suspected MEN1 syndrome [13]. Description in the text. Reprinted with permission of Oxford University Press. $\mathrm{CA}^{2+}$ — calcium ion; PTH — parathyroid hormone; PRL — prolactin; IGF-1 — insulina-like growth factor 1; CgA — chromogranin A; MRI - magnetic resonance imaging; CT — computed tomography; EUS - endoscopic ultrasonography

such frequent MRI scans, the safety of the examination without the use of gadolinium enhancement has been emphasised [29, 30].

\section{Manifestation and prognosis of MEN1 syndrome} In most cases $(83 \%)$, the clinical manifestation of the syndrome occurs after the age of 21 years of age; however, various components of MEN1 syndrome may occur in individuals younger than 10 years, in as many as $14 \%$ of patients [31]. No predilection has been described for age among aggressive tumours [31]. A multicentre analysis by Goudet et al. of the causes of death among patients with MEN1 syndrome showed that about $70 \%$ of them die as a result of diseases constituting the components of the syndrome. It has been established that gastrinoma (RR 1.9), non-secreting pancreatic tumour (RR 3.4) and glucagon, and somatostatin and VIP-secreting tumours (RR 4.3) are associated with higher risk of death. Diagnosis of an insulinoma, pituitary tumour or bronchial tumour did not affect the prognosis. Lower risk of death was observed in females, in cases of familial MEN1 syndrome and in cases diagnosed after 1980 [32]. The above-mentioned analysis emphasised the significant reduction in the number of deaths due to peptic ulcer observed since 1990, which is probably a result of the introduction of the use of proton pump inhibitors [33].

The treatment principles for individual tumours do not deviate from the standards developed for tumours unrelated to MEN1 syndrome, but the outcomes of treatment are not as favourable. Worse response is connected with a higher incidence of multiple tumours, which significantly limits the effectiveness of surgical procedures [14]. An example may be the long-term effects of surgical treatment of gastrinomas, which occur in MEN1 syndrome as multifocal submucosal tumours 
within the duodenum - in a five-year follow-up after surgery, no recurrence was observed in only $5 \%$ of patients with a MEN1 mutation, while in the group without MEN1 mutation this was true in $40 \%$ of cases [34, 35].

In the case of multiple parathyroid adenomas, characteristic for MEN1 syndrome, subtotal parathyroidectomy results in persistent/recurrent hypercalcaemia within 10 years in $20-60 \%$ of patients with MEN1 syndrome, compared to $4 \%$ in the group without MEN1 mutation [16, 36, 37]. The dissemination of neuroendocrine tumours is also more often observed in patients with MEN1 syndrome: insulin tumours in the course of MEN1 syndrome show the presence of metastatic lesions in almost $50 \%$ of cases (in sporadic tumours this is approximately 10\%) [38].

\section{Pituitary tumours in MEN1 syndrome}

The presence of a pituitary tumour is found in 15-50\% of patients with MEN1 syndrome $[9,13]$. It is rarely the first manifestation of the syndrome - only in about $15 \%$ of patients with the sporadic form of the syndrome (range from 10\% to 25\%) [39] and less than 10\% in the familial form [16].

Pituitary tumours related to MEN1 mutation are larger, more aggressive, and resistant to conventional therapy. $85 \%$ of tumours associated with the syndrome are macroadenomas, while among sporadic cases $42 \%$ were lesions above $1 \mathrm{~cm}$ [39]. The relationship between tumour invasiveness (grade III and IV according to the Vezina-Hardy grades classification, Tab. I) and the presence of a MEN1 mutation is not unambiguous: sporadic tumours were more frequently observed in grades I and III, while grades II and IV were dominated by tumours associated with the MEN1 syndrome [39].

Clinical manifestation is typical for particular types of hypersecretion; in the case of the most common prolactin-secreting tumour, there are galactorrhoea,

Table I. The classification of Vezina-Hardy-Wilson is based on anatomical and radiological correlation of pituitary tumours. Distinguishes five stages of tumour development based on size and expansion beyond the sella turcica

\begin{tabular}{cl}
\hline Grade I & $\begin{array}{l}\text { Microadenoma - a pituitary tumour, size less than } \\
10 \mathrm{~mm}\end{array}$ \\
\hline Grade II & $\begin{array}{l}\text { Macroadenomas — tumour larger than } 10 \mathrm{~mm} \text {, but } \\
\text { not destroying the bone structure of the sella turcica }\end{array}$ \\
\hline Grade III & $\begin{array}{l}\text { Tumours exhibiting local invasiveness, enlargement } \\
\text { of the sella turcica, and erosion of bone wall }\end{array}$ \\
\hline Grade IV & $\begin{array}{l}\text { Invasive tumours causing extensive destruction } \\
\text { of the bony walls of the sella turcica }\end{array}$ \\
\hline Grade V & $\begin{array}{l}\text { The tumour of the sella turcica with the presence } \\
\text { of blood-borne or cerebrospinal fluid metastases [40] }\end{array}$ \\
\hline
\end{tabular}

menstrual disorders (including secondary absence of menstruation), infertility, and libido disorders. Clinical symptoms (headaches or defects in the visual field) are more often associated with MEN1-related tumours (14\% to $29 \%$ ) [39]. MEN1-related pituitary tumours occur more frequently in women than in men, similarly as in the case of pituitary tumours in general $[39,41]$. Pituitary tumours associated with MEN1 syndrome occur in younger age groups compared to sporadic tumours $[9,13]$. In Carty's studies, the average age of diagnosis was 39.8 years (from 18 to 73 years). Based on a prospective analysis, penetrance was estimated at $28 \%$ at the age of 30 years, $48 \%$ at the age of 50 years, and $64 \%$ at the age of 70 years [42]. The majority of pituitary tumours are hormonally active: about $60 \%$ secrete prolactin, $25 \%$ growth hormone, $5 \%$ adrenocorticotropic hormone; the rest are non-secretory tumours [13, 43]. The percentage of hormonally active MEN1-related pituitary tumours is not significantly different than the percentage in sporadic tumours [41], but MEN1-related tumours more often secrete more than one hormone (39\% of tumours) $[9,41]$. This may be the reason for discrepancies in the distribution of hypersecretion shown in the literature [41]. The most common type of mixed tumour is prolactin and adrenocorticotropin-secreting tumour (PRL - ACTH), which is extremely rare among tumours without mutations in the MEN1 gene [41].

In addition to mixed tumours, there are also multiple tumours observed which are clinically difficult to distinguish from the pituitary hyperplasia described in autopsy studies of pituitaries of patients with MEN1 mutations [41]. However, no nuclear or cytoplasmic features that characterise MEN1-related tumours have been established except for increased immunoreactivity of S100 protein antibodies [41]. There are no histopathological features to distinguish pituitary tissue derived from sporadic tumours from familial or MEN1-related tumours [44]. Hyperplasia may result from the ectopic production of liberins. The literature reviews cases of patients with MEN1 syndrome with clinical and biochemical indicators of acromegaly without pituitary lesion (confirmed in the autopsy study). The causes of growth hormone excess were neuroendocrine pancreatic tumours secreting somatoliberin [41, 45-47]. There are also other examples of ectopic GHRH secretion $[48,49]$.

Despite the tendency to be more invasive with worse response to treatment and larger size, there was no higher incidence of malignant transformation compared to sporadic tumours. So far, three cases of pituitary cancer have been described in patients with pituitary tumour associated with a pathogenic variant of MEN1. The first concerned a woman with sporadic MEN1 syndrome and a gonadotropin-secreting tumour 
[50], the second - a man with a tumour secreting prolactin and familial MEN1 syndrome [51], and the third - a man with a tumour producing thyroid-stimulating hormone in the course of sporadic MEN1 syndrome [52]. To date, no definite markers have been found that allow for early identification of a malignant tumour. The diagnosis of cancer is based on the presence of local (in the central nervous system) or distant metastases [25].

The therapy of pituitary tumours in patients with a confirmed mutation in the MEN1 gene does not deviate from routine management. It is based on the use of standard therapy, i.e. cabergoline/bromocriptine in the case of a prolactin tumour and neurosurgical treatment preceded by the preparatory use of lanreotide/octreotide in somatotropic tumours. Depending on the clinical situation, reoperation and/or radiotherapy for residual tumour mass is performed [3]. In the case of biologically aggressive tumours (the presence of at least one among: Ki-67 $\geq 3 \%$ and/or increased mitotic value $>2$ and/or p53 protein expression), temozolomide therapy is used $[25,53]$.

MEN1-related pituitary tumours show a worse response to the above therapies measured by normalisation of pituitary hormone concentrations, which was achieved in $42 \%$ of patients with MEN1-related tumours compared to $90 \%$ efficacy in the population of patients with sporadic tumours [39]. In addition, the analysis of treatment effectiveness of the most common type of hypersecretion - prolactinoma - showed normalisation of prolactin concentration in only $44 \%$ of patients. The above data suggest that patients with pituitary tumours as a result of a mutation in the MEN1 gene are a group of patients more frequently undergoing neurosurgical treatment due to the lack of response to pharmacological treatment [14].

The absence of such a correlation was demonstrated by Danish researchers. Among 323 people with MEN1, $123(38.1 \%)$ had a pituitary tumour with an average size of $8.9 \pm 0.7 \mathrm{~mm}$; in subsequent imaging of microadenomas, they did not show a significant increase in tumour size. The response to treatment in the whole group did not significantly differ from the general population: efficacy was estimated at $>90 \%$ [54].

The decision regarding surgical treatment of a prolactin-secreting tumour is usually made after pharmacological treatment. According to the guidelines of the Endocrine Society, indications for surgical treatment of prolactinoma are: 1) pressure on the optic chiasm causing visual field defects and 2) lack of normalisation of prolactin concentration and reduction of tumour size in the control MRI despite the use of the maximally tolerated cabergoline dose [3]. In cases where treatment with bromocriptine has been initiated and therapeutic success has not been achieved, the decision on neu- rosurgical management should be preceded by using cabergoline. So far, no studies have been published that compare the effectiveness of tumour volume reduction using different dopamine agonists, but in available studies, the reduction of prolactin tumour size was achieved in $50 \%$ of patients treated with bromocriptine and in $90 \%$ of patients treated with cabergoline $[3,55]$. The tolerance of therapy and the economic barrier of the availability of the medicine remain a separate issue.

\section{Conclusions}

MEN1 is a rare disease with a complicated and still poorly understood course. The diagnosis and treatment of MEN1-related pituitary tumours is an important and difficult task for clinicians.

MEN1-related tumours are larger, more aggressive, resistant to conventional therapy, and occur in younger age groups compared to sporadic tumours. Patients with MEN1 syndrome have a reduced life expectancy, and the results of treatment of individual components of the syndrome (including pituitary tumours) are significantly worse than the treatment of similar tumours in patients without MEN1 mutations.

The effectiveness of treatment and survival prognosis in patients with MEN1 syndrome may be improved by using early, evidence-based diagnosis and treatment. Patients and their families should remain under the care of specialised endocrinological centres experienced in the diagnosis and treatment of all components of the syndrome and with full diagnostic facilities (genetic laboratory, SPECT, SRS, MR), cooperating with an experienced neurosurgeon, radiologist, and oncologist. Further studies investigating early diagnostic markers and markers of the response to treatment should be carried out. There is also a need to create updated guidelines of the diagnosis and treatment to improve the effectiveness of the care of patients with MEN1 mutations.

\section{Funding}

The authors did not receive any specific grant from any funding agency in the public, commercial, or not-for-profit sector.

\section{Conflicts of interests}

The authors declare none.

\section{Author contributions}

The first authorship of D.R. and A.G.J. is of equal rank.

\section{References}

1. Ezzat S, Asa SL, Couldwell WT, et al. The prevalence of pituitary adenomas: a systematic review. Cancer. 2004; 101(3): 613-619, doi: 10.1002/cncr.20412, indexed in Pubmed: 15274075. 
2. Newey PJ, Gorvin CM, Cleland SJ. Mutant prolactin receptor and familial hyperprolactinemia. N Engl J Med. 2013; 369(21): 2012-2020, doi: 10.1056/NEJMoa1307557, indexed in Pubmed: 24195502.

3. Melmed S, Casanueva FF, Hoffman AR, et al. Endocrine Society. Diagnosis and treatment of hyperprolactinemia: an Endocrine Society clinical practice guideline. J Clin Endocrinol Metab. 2011; 96(2): 273-288, doi: 10.1210/jc.2010-1692, indexed in Pubmed: 21296991.

4. Fernandez A, Karavitaki N, Wass JAH. Prevalence of pituitary adenomas: a community-based, cross-sectional study in Banbury (Oxfordshire, UK). Clin Endocrinol (Oxf). 2010; 72(3): 377-382, doi: 10.1111/j.1365-2265.200 9.03667.x, indexed in Pubmed: 19650784.

5. Daly AF, Rixhon M, Adam C, et al. High prevalence of pituitary adenomas: a cross-sectional study in the province of Liege, Belgium. J Clin Endocrinol Metab. 2006; 91(12): 4769-4775, doi: 10.1210/jc.2006-1668, indexed in Pubmed: 16968795.

6. Caimari F, Korbonits M. Novel Genetic Causes of Pituitary Adenomas. Clin Cancer Res. 2016; 22(20): 5030-5042, doi: 10.1158/1078-0432. CCR-16-0452, indexed in Pubmed: 27742789.

7. Marques P, Korbonits M. Genetic Aspects of Pituitary Adenomas. Endocrinol Metab Clin North Am. 2017; 46(2): 335-374, doi: 10.1016/j. ecl.2017.01.004, indexed in Pubmed: 28476226.

8. Falchetti A, Marini F, Luzi E, et al. Multiple endocrine neoplasia type 1 (MEN1): not only inherited endocrine tumors. Genet Med. 2009, 11(12): 825-835, doi: 10.1097/GIM.0b013e3181be5c97, indexed in Pubmed: 19904212.

9. Syro LV, Scheithauer BW, Kovacs K, et al. Pituitary tumors in patients with MEN1 syndrome. Clinics (Sao Paulo). 2012; 67(Suppl 1): 43-48, doi: 10.6061/clinics/2012(Sup01)09, indexed in Pubmed: 22584705.

10. Underdahl LO, Woolner LB, Black BM. Multiple endocrine adenomas; report of 8 cases in which the parathyroids, pituitary and pancreatic islets were involved. J Clin Endocrinol Metab. 1953; 13(1): 20-47, doi: 10.1210/jcem-13-1-20, indexed in Pubmed: 13022748

11. Wermer P. Genetic aspects of adenomatosis of endocrine glands. Am J Med. 1954; 16(3): 363-371, doi: 10.1016/0002-9343(54)90353-8, indexed in Pubmed: 13138607.

12. Chandrasekharappa SC, Guru SC, Manickam P, et al. Positional cloning of the gene for multiple endocrine neoplasia-type 1. Science. 1997; 276(5311): 404-407, doi: 10.1126/science.276.5311.404, indexed in Pubmed: 9103196.

13. Thakker RV. Multiple endocrine neoplasia type 1 (MEN1). Best Pract Res Clin Endocrinol Metab. 2010; 24(3): 355-370, doi: 10.1016/j. beem.2010.07.003, indexed in Pubmed: 20833329

14. Thakker RV, Newey PJ, Walls GV, et al. Endocrine Society. Clinical practice guidelines for multiple endocrine neoplasia type 1 (MEN1). Clin Endocrinol Metab. 2012; 97(9): 2990-3011, doi: 10.1210/jc.2012-1230, indexed in Pubmed: 22723327.

15. Corbetta S, Pizzocaro A, Peracchi M, et al. Multiple endocrine neoplasia type 1 in patients with recognized pituitary tumours of differen types. Clin Endocrinol (Oxf). 1997; 47(5): 507-512, doi: 10.1046/j.1365-2 265.1997.3311122.x, indexed in Pubmed: 9425388.

16. Brandi ML, Gagel RF, Angeli A, et al. Guidelines for diagnosis and therapy of MEN type 1 and type 2. J Clin Endocrinol Metab. 2001; 86(12): 5658-5671, doi: 10.1210/jcem.86.12.8070, indexed in Pubmed: 11739416.

17. Stratakis CA, Schussheim DH, Freedman SM, et al. Pituitary macroadenoma in a 5-year-old: an early expression of multiple endocrine neoplasia type 1. J Clin Endocrinol Metab. 2000; 85(12): 4776-4780, doi: 10.1210/jcem.85.12.7064, indexed in Pubmed: 11134142

18. Falchetti A. Genetic screening for multiple endocrine neoplasia syndrome type 1 (MEN-1): when and how. F1000 Med Rep. 2010; 2 , doi: 10.3410/M2-14, indexed in Pubmed: 20948872.

19. Machens A, Schaaf L, Karges W, et al. Age-related penetrance of endocrine tumours in multiple endocrine neoplasia type 1 (MEN1) a multicentre study of 258 gene carriers. Clin Endocrinol (Oxf). 2007; 67(4): 613-622, doi: 10.1111/j.1365-2265.2007.02934.x, indexed in Pubmed: 17590169.

20. Lemos MC, Thakker RV. Multiple endocrine neoplasia type (MEN1): analysis of 1336 mutations reported in the first decade following identification of the gene. Hum Mutat. 2008; 29(1): 22-32, doi: 10.1002/humu.20605, indexed in Pubmed: 17879353.

21. Bassett JH, Forbes SA, Pannett AA, et al. Characterization of mutations in patients with multiple endocrine neoplasia type 1 . Am J Hum Genet. 1998; 62(2): 232-244, doi: 10.1086/301729, indexed in Pubmed: 9463336.

22. Turner JJO, Leotlela PD, Pannett AAJ, et al. Frequent occurrence of an intron 4 mutation in multiple endocrine neoplasia type 1 . J Clin Endocrinol Metab. 2002; 87(6): 2688-2693, doi: 10.1210/jcem.87.6.8607, indexed in Pubmed: 12050235.

23. Starker LF, Akerström T, Long WD, et al. Frequent germ-line mutations of the MEN1, CASR, and HRPT2/CDC73 genes in young patient with clinically non-familial primary hyperparathyroidism. Horm Cancer. 2012; 3(1-2): 44-51, doi: 10.1007/s12672-011-0100-8, indexed in Pubmed: 22187299.
24. Jensen RT, Berna MJ, Bingham DB, et al. Inherited pancreatic endocrine tumor syndromes: advances in molecular pathogenesis, diagnosis, management, and controversies. Cancer. 2008; 113(7 Suppl): 1807-1843, doi: 10.1002/cncr.23648, indexed in Pubmed: 18798544

25. Raverot G, Burman P, McCormack A, et al. European Society of Endocrinology. European Society of Endocrinology Clinical Practice Guidelines for the management of aggressive pituitary tumours and carcinomas. Eur J Endocrinol. 2018; 178(1): G1-G24, doi: 10.1530/EJE-17-0796, indexed in Pubmed: 29046323.

26. Skalniak A, Sokołowski G, Jabrocka-Hybel A, et al. A novel in-frame deletion in MEN1 (p.Ala416del) causes familial multiple endocrine neoplasia type 1 with an aggressive phenotype and unexpected inheritance pattern. Mol Med Rep. 2016; 14(3): 2061-2066, doi: 10.3892/mmr.2016.5462, indexed in Pubmed: 27430871.

27. Multiple Endocrine Neoplasia Type 1 (MEN1) Workup: Approach Considerations, Laboratory Studies, Imaging Studies. https:/emedicine. medscape.com/article/126438-workup (February 25, 2019).

28. MEN1 screening protocol (Published January 2017). http://www.edinburghdiabetes.com/s/2017-02-01-MEN1-Screening.docx.

29. Drug Safety and Availability - FDA Drug Safety Communication: FDA evaluating the risk of brain deposits with repeated use of gadolinium-based contrast agents for magnetic resonance imaging (MRI) (Published July 25, 2015)). https://www.fda.gov/Drugs/DrugSafety/ucm455386.htm (Accessed February 25, 2019.).

30. Stojanov D, Aracki-Trenkic A, Benedeto-Stojanov D. Gadolinium deposition within the dentate nucleus and globus pallidus after repeated administrations of gadolinium-based contrast agents - current status. Neuroradiology. 2016; 58(5): 433-441, doi: 10.1007/s00234-016-1658-1, indexed in Pubmed: 26873830

31. Goudet P, Dalac A, Le Bras M, et al. MEN1 disease occurring before 21 years old: a 160-patient cohort study from the Groupe d'étude des Tumeurs Endocrines. J Clin Endocrinol Metab. 2015; 100(4): 1568-1577, doi: 10.1210/jc.2014-3659, indexed in Pubmed: 25594862.

32. Goudet $\mathrm{P}$, Murat A, Binquet $\mathrm{C}$, et al. Risk factors and causes of death in MEN1 disease. A GTE (Groupe d'Etude des Tumeurs Endocrines) cohort study among 758 patients. World J Surg. 2010; 34(2): 249-255, doi: 10.1007/s00268-009-0290-1, indexed in Pubmed: 19949948

33. Sachs G, Shin JM, Howden CW. Review article: the clinical pharmacology of proton pump inhibitors. Aliment Pharmacol Ther. 2006; 23(s2): 2-8, doi: 10.1111/j.1365-2036.2006.02943.x, indexed in Pubmed: 16700898 .

34. Tonelli F, Fratini $G$, Nesi $G$, et al. Pancreatectomy in multiple endocrine neoplasia type 1-related gastrinomas and pancreatic endocrine neoplasias. Ann Surg. 2006; 244(1): 61-70, doi: 10.1097/01. sla.0000218073.77254.62, indexed in Pubmed: 16794390.

35. Norton JA, Fraker DL, Alexander HR, et al. Surgery to Cure the Zollinger-Ellison Syndrome. N Engl J Med. 1999; 341(9): 635-644, doi: 10.1056/NEJM199908263410902, indexed in Pubmed: 10460814.

36. Waldmann J, López CL, Langer $\mathrm{P}$, et al Surgery for multiple endocrine neoplasia type 1-associated primary hyperparathyroidism. Br J Surg. 2010; 97(10): 1528-1534, doi: 10.1002/bjs.7154, indexed in Pubmed: 20629112

37. Schreinemakers JMJ, Pieterman CRC, Scholten A, et al. The optimal surgical treatment for primary hyperparathyroidism in MEN1 patients: a systematic review. World J Surg. 2011; 35(9): 1993-2005, doi: 10.1007/s00268-011-1068-9, indexed in Pubmed: 21713580.

38. Akerström G, Hellman P. Surgery on neuroendocrine tumours. Best Pract Res Clin Endocrinol Metab. 2007; 21(1): 87-109, doi: 10.1016/j. beem.2006.12.004, indexed in Pubmed: 17382267.

39. Vergès B, Boureille $F$, Goudet $P$, et al. Pituitary disease in MEN type 1 (MEN1): data from the France-Belgium MEN1 multicenter study. J Clin Endocrinol Metab. 2002; 87(2): 457-465, doi: 10.1210/jcem.87.2.8145, indexed in Pubmed: 11836268.

40. Wilson-Hardy classification. NeuroMind.cc. https://www.neuromind. cc/tumor/wilson-hardy-classification/ (March 5, 2019).

41. Trouillas J, Labat-Moleur F, Sturm N, et al. Groupe d'études des Tumeurs Endocrines. Pituitary tumors and hyperplasia in multiple endocrine neoplasia type 1 syndrome (MEN1): a case-control study in a series of 77 patients versus 2509 non-MEN1 patients. Am J Surg Pathol. 2008; 32(4): 534-543, doi: 10.1097/PAS.0b013e31815ade45, indexed in Pubmed: 18300794.

42. Carty SE, Helm AK, Amico JA, et al. The variable penetrance and spectrum of manifestations of multiple endocrine neoplasia type 1 . Surgery. 1998; 124(6): 1106-1114, doi: doi:10.1067/msy.1998.93107, indexed in Pubmed: 9854591

43. Horvath A, Stratakis CA. Clinical and molecular genetics of acromegaly: MEN1, Carney complex, McCune-Albright syndrome, familial acromegaly and genetic defects in sporadic tumors. Rev Endocr Metab Disord. 2008; 9(1): 1-11, doi: 10.1007/s11154-007-9066-9, indexed in Pubmed: 18200440

44. Saeger W, Petersenn S, Schöfl C, et al. Emerging Histopathological and Genetic Parameters of Pituitary Adenomas: Clinical Impact and Recom- 
mendation for Future WHO Classification. Endocr Pathol. 2016; 27(2): 115-122, doi: 10.1007/s12022-016-9419-6, indexed in Pubmed: 26874696.

45. Garby L, Caron P, Claustrat F, et al. GTE Group. Clinical characteristics and outcome of acromegaly induced by ectopic secretion of growth hormone-releasing hormone (GHRH): a French nationwide series of 21 cases. J Clin Endocrinol Metab. 2012; 97(6): 2093-2104, doi: 10.1210/jc.2011-2930, indexed in Pubmed: 22442262

46. Saleem TF, Santhanam P, Hamoudeh E, et al. Acromegaly caused by growth hormone releasing hormone (GHRH) secreting tumor in multiple endocrine neoplasia (MEN-1). W V Med J. 2012; 108(2): 26-30, indexed in Pubmed: 22655432.

47. Berger G, Trouillas J, Bloch B, et al. Multihormonal carcinoid tumor of the pancreas. Secreting growth hormone-releasing factor as a cause of acromegaly. Cancer. 1984; 54(10): 2097-2108, doi: 10.1002/1097-0142(19841115)54:10<2097::AID-CNCR2820541009> 3.0.CO;2-X, indexed in Pubmed: 6435852.

48. Stelmachowska-Banaś M, Głogowski M, Vasiljevic A, et al. Ectopic acromegaly due to growth hormone-releasing hormone secretion from bronchial carcinoid causing somatotroph hyperplasia and partial pituitary insufficiency. Pol Arch Intern Med. 2019; 129(3): 208-210, doi: 10.20452/pamw.4413, indexed in Pubmed: 30608060.

49. Bolanowski M, Schopohl J, Marciniak M, et al. Acromegaly due to GHRH-secreting large bronchial carcinoid. Complete recovery following tumor surgery. Exp Clin Endocrinol Diabetes. 2002; 110(4): 188-192, doi: 10.1055/s-2002-32151, indexed in Pubmed: 12058343.
50. Benito M, Asa SL, Livolsi VA, et al. Gonadotroph tumor associated with multiple endocrine neoplasia type 1. J Clin Endocrinol Metab. 2005; 90(1): 570-574, doi: 10.1210/jc.2004-1373, indexed in Pubmed: 15522929.

51. Gordon MV, Varma D, McLean CA, et al. Metastatic prolactinoma presenting as a cervical spinal cord tumour in multiple endocrine neoplasia type one (MEN-1). Clin Endocrinol (Oxf). 2007; 66(1): 150-152, doi: 10.1 111/j.1365-2265.2006.02697.x, indexed in Pubmed: 17201817.

52. Scheithauer BW, Kovacs K, Nose V, et al. Multiple endocrine neoplasia type 1-associated thyrotropin-producing pituitary carcinoma: report of a probable de novo example. Hum Pathol. 2009; 40(2): 270-278, doi: 10.1016/j.humpath.2008.06.013, indexed in Pubmed: 18755492.

53. Gilis-Januszewska A, Wilusz M, Pantofliński J, et al. Temozolomide therapy for aggressive pituitary Crooke's cell corticotropinoma causing Cushing's Disease - a case report with literature review. Endokrynol Pol. 2018; 69(3): 306-312, doi: 10.5603/EP.a2018.0011, indexed in Pubmed: 29319131.

54. de Laat JM, Dekkers OM, Pieterman CRC, et al. Long-Term Natural Course of Pituitary Tumors in Patients With MEN1: Results From the DutchMEN1 Study Group (DMSG). J Clin Endocrinol Metab. 2015; 100(9): 3288-3296, doi: 10.1210/JC.2015-2015, indexed in Pubmed: 26126205.

55. Molitch ME, Elton RL, Blackwell RE, et al. Bromocriptine as primary therapy for prolactin-secreting macroadenomas: results of a prospective multicenter study. J Clin Endocrinol Metab. 1985; 60(4): 698-705, doi: 10.1210/jcem-60-4-698, indexed in Pubmed: 3882737. 